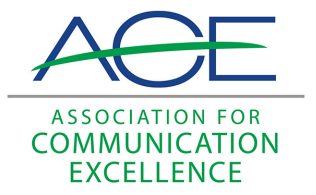

Journal of Applied Communications

\title{
A Mnemonic Based on Arranging Words on Visual Patterns; Performance Improvement Quarterly; The Cooperative Extension Service; Instant Health Information: Serving Needs of Rural Residents
}

Debrah Jefferson

Jim King

Greg Nolting

See next page for additional authors

Follow this and additional works at: https://newprairiepress.org/jac (c) (1) (2)(2)

This work is licensed under a Creative Commons Attribution-Noncommercial-Share Alike 4.0 License.

\section{Recommended Citation}

Jefferson, Debrah; King, Jim; Nolting, Greg; and Shaner, Jim (1988) "A Mnemonic Based on Arranging Words on Visual Patterns; Performance Improvement Quarterly; The Cooperative Extension Service; Instant Health Information: Serving Needs of Rural Residents," Journal of Applied Communications: Vol. 71: Iss. 2. https://doi.org/10.4148/1051-0834.1557

This Review is brought to you for free and open access by New Prairie Press. It has been accepted for inclusion in Journal of Applied Communications by an authorized administrator of New Prairie Press. For more information, please contact cads@k-state.edu. 


\title{
A Mnemonic Based on Arranging Words on Visual Patterns; Performance Improvement Quarterly; The Cooperative Extension Service; Instant Health Information: Serving Needs of Rural Residents
}

\author{
Abstract \\ Bernice A. Epstein. \\ Authors \\ Debrah Jefferson, Jim King, Greg Nolting, and Jim Shaner
}

Reviews of "A Mnemonic Based on Arranging Words on Visual Patterns," by Francis S. Belezza; Performance Improvement Quarterly, The Cooperative Extension Service: A National Assessment, by Paul D. Warner and lames A. Christenson; "Instant Health Information: Serving Needs of Rural Residents" by 


\section{Reviews}

"A Mnemonic Based on Arranging Words on Visual Patterns," by Francis S. Belezza in the Journal of Educational Psychology, 78 (31), (1986), pp. 217-224.

Extension and agricultural information specialists who develop training material will find Belezza's research useful. Belezza demonstrates how arranging word lists on distinctive visual patterns, and how using stories as mnemonic devices, aids recall. Belezza's research suggests the considered use of visual patterns and backgrounds when preparing charts, posters, slides or printed material for training purposes. His conclusions were based upon three year-long experiments using the same college students. A test-retest, within-group design was used.

In the first experiment, lists of concrete nouns were placed on the same background, as well as on different visual backgrounds. When students were tested immediately and, again, one week later, results showed that recall was enhanced by using different drawings on visual patterned backgroundswithout relationship to the word lists.

However, the journal's lack of graphics may have clouded the presentation. For, without graphics, the illustration seemed to imply that the words were arranged in a visual pattern themselves and that the arrangement of words was the pattern tested.

The second experiment was conducted to test whether the results in the first experiment were valid when a word list-relevant to the subject which students wanted to remember--was used. In this experiment, drawings related to the word lists and unrelated drawings were used (see Table 1). Results confirm that recall was improved when different drawings or visual backgrounds were used as a mnemonic aid. The closer the drawing's content was to the content of the word list, the better the recall.

Table 1.

Sample Cue Word, Drawing and Word Lists for Experiment Two:

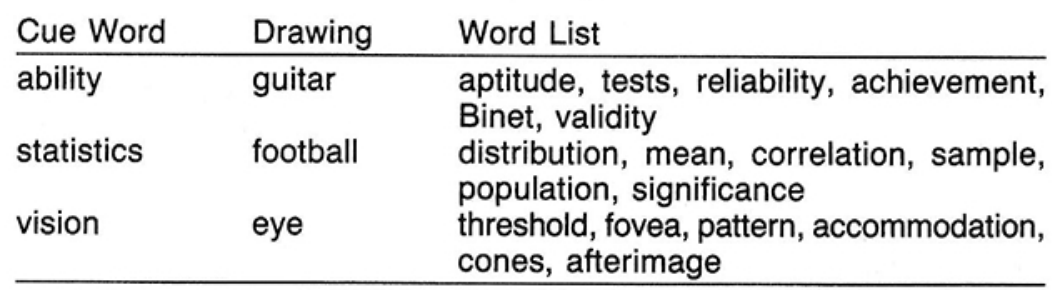

The third experiment tested whether incorporating words into a story form helped recall (Figure 2). Experiment Three incorporated word lists into a story mnemonic and compared the results with those using words on a visualpattern or drawing as the mnemonic aid. Results showed that better recall was achieved when stories were given. 


\section{Word List in Story for Experiment Three:}

\section{Frog (cue word)}

The frog was hit by a lemon while smelling a flower. $\mathrm{He}$ opened a door and fell into an old volcano. There he ate some corn and put on a dress.

Belezza attributed the results to possible discrimination skills within the students that enhanced recall ability. By placing words on distinctive visual patterns, he surmised, the discrimination increased and recall performance was enhanced. By using stories or visual cues related to the words to be recalled, memory was enhanced.

$\mathrm{He}$ recommended more research to check for novelty effect in his experiments. That may be reflected in the nonsense theme to the story, in particular. The varied drawings or stories may have caused the students to pay more attention because they were different.

Information specialists can put Belezza's findings to practical use because the diverse visual background can help the student retain information by stimulating interest, especially when cue words and backgrounds are related to the items being taught or presented. Information specialists involved in continuous training programs or who develop instructional materials may achieve better results by trying Belezza's idea.

\section{Performance Improvement Quarterly. National Society for Perfor- mance and Instruction, 1126 16th Street, N.W., Washington, D.C. 20036 (Annual, \$20 domestic; \$15 for NSPI members; \$11 students; $\$ 32$ institutions).}

Something old: The National Society for Performance and Instruction has been working and publishing journals for over 25 years in the area of human performance technology.

Something new: This fresh new quarterly is dedicated to help professionals improve the performance of people through better designed learning and training activities.

Something borrowed: Content for the initial volume of PIQ comes from a broad mixture of disciplines-medicine, education, organizational development, human resources.

Something blue: A very crisp blue cover sparks the premier edition.

NSPI defines performance technology as a "set of methods and processes for solving problems and realizing opportunities related to the performance of people." Thus the first issue has lead articles on mastery learning, instructional design, job aids in medicine, motivation and organization, performance without training.

In the instructions to authors, PIQ notes that it wants to "emphasize original work involving technologies such as front-end analysis or evaluation, and 
interventions such as motivation, personnel selection, instruction, ergonomics, or guidance."

Carrying through with this emphasis, the first issue presents an excellent article by Robert Gagne. Gagne, one of the instructional technology pioneers (on the psychology side), elaborates on his well-known learning conditions, discussing different conditions for different outcomes.

The journal also promises some smiles. A section called "Abstract at The Least-Reviews of Data-Based Studies of A Whimsical Nature" offers what its title suggests. The first review is on the use of a self-report measure of learner interest/yawning frequency. The study confirms the popular "belief that a yawn is a 'paralinguistic signal for drowsiness, fatigue, disinterest, and boredom." "

This journal is off to a superb start. Articles deliver summaries, visions, and practical methods. For ACE readers who have an interest in and responsibility for training and instructional activities-especially non-formal education-PIQ will provide pleasant intellectual stimulation with examples of applications. And, it offers those ACE members who are researching and publishing a wonderful opportunity because no one is writing on human performance technology in the agricultural sector.

Jim King

University of Nebraska-Lincoln

The Cooperative Extension Service: A National Assessment by Paul D. Warner and James A. Christenson. 1984. Westview Press, Inc. 5500 Central Avenue, Boulder, Colorado 80301, 188 pp.

Warner and Christenson do an effective job of increasing the reader's understanding of the complex organization called Extension. In part, this is done by describing the users of Extension services and their satisfaction/dissatisfaction with those services.

That description stems from the national assessment survey completed in 1982. The data profile existing programs well and provide insights regarding the type of organization needed in the 21 st century. Warner and Christenson discuss the county, state and federal sociopolitical environment and its relationship to Extension.

So, congressmen, legislators, and representatives of county government probably have already read this book!

Public awareness of Extension programs is very good. For example, in the Northeast, $85 \%$ are aware of the name Extension-or at least are aware of one of its programs. The South ranked the highest in awareness with $91 \%$. Although the totals of those in Extension's different audiences is impressive, its overall recognition by individual audiences is not. For example, Extension's name is recognized by only $40 \%$. Program areas of home economics and community development were recognized by $45 \%$ and $46 \%$, respectively. Agriculture and $4 \mathrm{H} /$ Youth received the highest recognition, with $52 \%$ and $77 \%$, respectively.

Other data indicate overwhelming support by the users of Extension programs, as well as by the general public. However, the older population is much more supportive than the young.

The data dispell some popular notions: $64 \%$ of those who use Extension 
services are in metropolitan areas. The satisfaction level for non-white vs. white users was $69 \%$ and $72 \%$. But, Extension still serves a larger percentage of the rural population. And the satisfaction level tends to increase with educational level, income, and farm size. In general, nearly every user category was supportive of Extension's efforts.

This book should be of particular interest to ACE communicators. It attempts to chart the course of Extension as it enters the information age. Although the data provide little insight regarding the exact amount and types of change, common sense suggests-if extension is to survive-it must change as this country continues to change from an industrial to an informational society.

Greg Nolting

University of Missouri-Columbia

\section{"Instant Health Information: Serving Needs of Rural Residents" by Bernice A. Epstein in Journal of Extension, (Spring 1988), Extension Journal Inc., Madison, Wisconsin, pp. 14-17.}

Bernice A. Epstein, an extension specialist in health and safety at the University of Arizona, Tucson, reports on the marketing approaches used to promote a toll-free, state-wide telephone service called Instant Health Info. The marketing effort began "six weeks after the initial burst of free publicity when calls began to decline."

Seven different marketing techniques were used, the health and safety specialist reports, from 1 to 25 times each, over 18 months. All involved printing. No broadcast promotion was included.

In print, the Instant Health Info program was promoted through advertising, the reprinting of its directory of 350 topics in both regular newspapers and in advertising supplements, through direct mail, through inserts in both advertising supplements and in regular newspapers. It was also promoted through distributing the directories in schools. Epstein reports the promotions were tried all days of the week and were spaced at least two weeks apart, except for newspaper advertising.

Ads were repeated several times a week and/or on consecutive weeks. They ran an average of 15 column-inches and were professionally designed; they included a picture of a telephone, copy describing the service and the number to call for a free directory.

Promotional costs varied, with the reprinting of the directory in newspapers among the least expensive because sponsors solicited by the newspapers paid the bill. Reprinting in advertising supplements cost an average of .014 cents per copy. Inserts in subscriber newspaper and advertising supplements averaged $4 \frac{1}{2}$ cents per copy; advertising averaged $\$ 73$ an ad. 
Jefferson et al.: A Mnemonic Based on Arranging Words on V isual Patterns; Performan Epstein established a base rate for tepephone queries to better measure the impact of marketing. To establish the base, she averaged the calls for a fourweek period in each county for each year when no specific publicity was underway. Then she added a margin to that base to account for chance variation. So more calls than that adjusted base were counted as "new" calls. The cost of the new calls ranged from nothing, presumably for the sponsored supplement, to $\$ 4.56$.

The most effective marketing technique, in terms of the number of calls generated, was distributing the directories via elementary school youngsters. Reprinting the directory in advertising supplements ranked next. That was followed by inserts in regular newspapers, inserts in advertising supplements, direct mail, reprints in regular newspapers, and advertising.

Epstein found no relationship between the size of the ad, or variations in frequency, and the number of new calls generated. In other words, ads running only once, drew no worse than ads run once a week for two weeks, or those run on subsequent days during one or two weeks. Cost per new call averaged $\$ 4.56$. Ad rates ranged from $\$ 26$ to $\$ 440$, depending upon the population of the newspaper's circulation area.

The Arizona specialist concluded that the total amount spent on all paid promotion, $\$ 8,000$, was slightly less than the average salary for the average time spent by each extension specialist in promoting the program-one hour a week. But media promotion was much more effective. Of those, advertising supplements provided best. The supplements, together with school distribution, outdrew regular newspaper supplements, inserts, and advertising. 